\title{
Familial Brachydactyly in an Indian Family: A case report
}

\author{
Halder SK ${ }^{1}$, Khan I², Paira SK ${ }^{3}$, Mukherjee $\mathbf{R}^{4}$
}

${ }^{1}$ Dr. Sandip Kumar Halder, MBBS.MS. MRCS. FRCS. Assistant Professor. ${ }^{2}$ Dr. Imran Khan, MBBS. Post Graduate Trainee in Surgery, ${ }^{3} \mathrm{Dr}$. Susil Kumar Paira, MBBS.MS, Associate Professor. ${ }^{4} \mathrm{Dr}$. Ramanuj Mukherjee, MBBS. MS. MNAMS. MRCS Assistant Professor. All from the Department of Surgery, RG Kar Medical College, Kolkata, India.

Address for correspondence: Dr. SK Halder, E-mail: hsandip@hotmail.com

\begin{abstract}
Brachydactyly or short digit is a rare deformity involving fingers and toes. We present a rare family with 6 known members affected with similar pattern of brachydactyly, affecting only bilateral index fingers. The knowledge of this entity is important and a thorough clinical and radiological evaluation is mandatory for any patient with digital deformities.
\end{abstract}

\section{Introduction}

Brachydactyly (Greek: "short digits") is a general term that refers to disproportionately short fingers and toes, and forms part of the group of limb malformations characterized by bone dysostosis ${ }^{1}$. But it has a clinical spectrum ranging from minor digital hypoplasia to complete aplasia. Among the 10 clinical types described types $A 3$ and $D$ are relatively common isolated forms. Brachydactyly can occur either as an isolated malformation or as a part of a complex malformation syndrome ${ }^{1}$. Our patient was a case of brachydactyly type A2 (BDA2) with only index fingers affected. Her family history revealed similarly affected 6 members in four generations. We present this family with this rare disorder.

\section{Case report}

A 32-year-old female presented to the emergency department with recurrent paronychia of the right middle finger. She was treated surgically. On examination, she was found to have short bilateral index fingers in both her hands, present since her birth, without any associated problem. The index fingers were symmetrically short with absent middle phalanx and hypoplastic nails (Figure 1). There was no other systemic or skeletal abnormality. The toes were clinically normal.

The patient had a 2-year-old son who had similar abnormality. Her child was examined by the surgical and paediatric teams. The child had normal milestones of development. On examination, he also had no other skeletal abnormality. He was found normal on general and systemic examinations. The index fingers were symmetrically short (Figure 2 ). The toes were clinically normal.

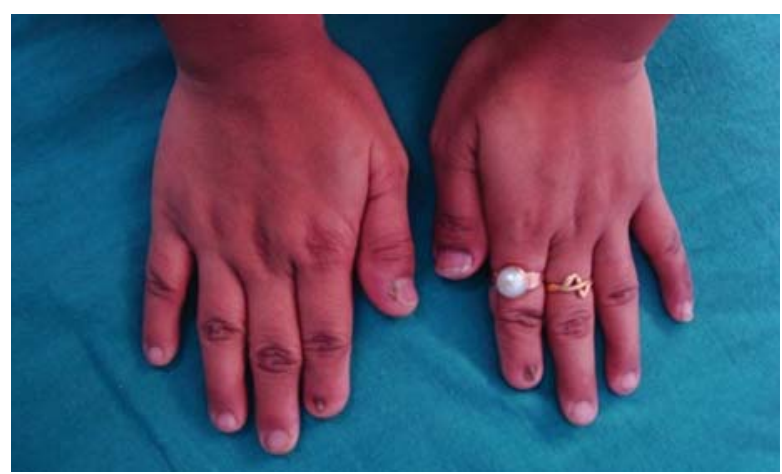

Fig 1: Hands with short index fingers and hypoplastic nails in mother (patient).

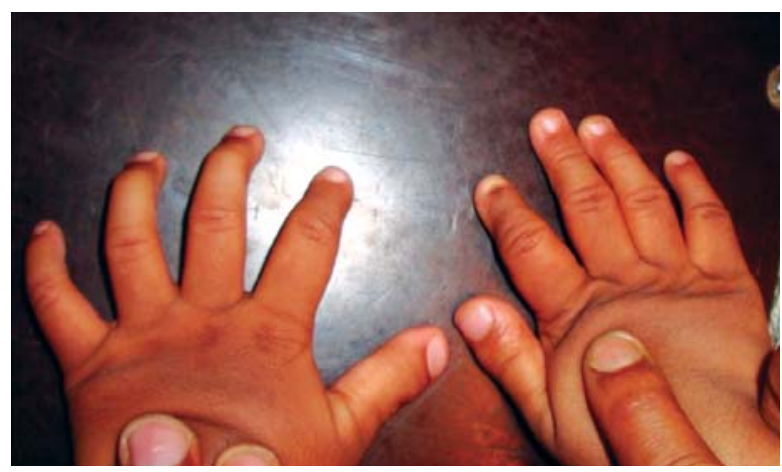

Fig 2: The hands of the child with hypoplastic index fingers. 
On further questioning she mentioned that her 4 other her family members had similar abnormality (Fig 3). Two of them were not alive and the two other members are living in another part of the country. All the affected members who died had death from known causes and they were apparently normal and had reasonably long life. The family is spread over different places in India. Various family members were contacted by telephone and a family pedigree was charted by compiling the history obtained from all the sources. Most of the sources were quite confident about their memory. There was no other information available regarding the previous generations. There was no known history of any consanguineous marriage. The patient didn't wish to go for further radiological examination.

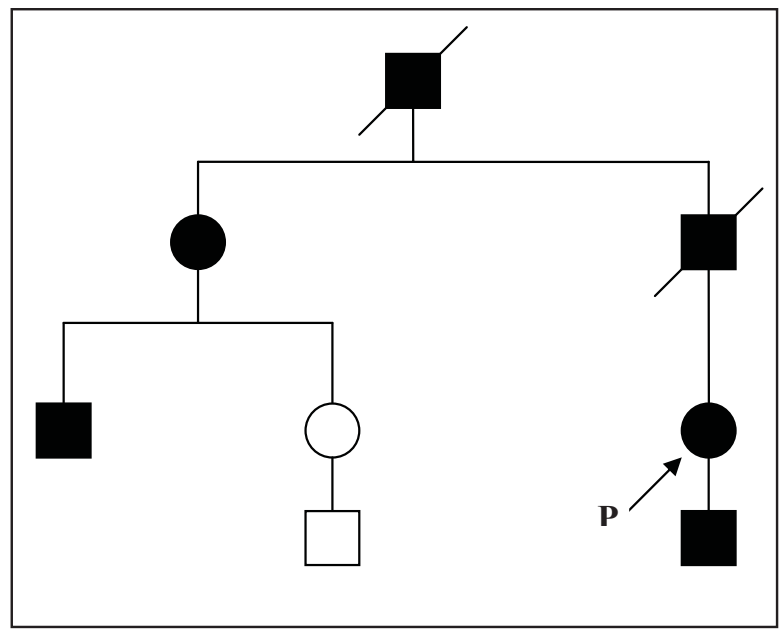

Fig 3: Family pedigree proband.

\section{Discussion}

The term brachydactyly is derived from the ancient Greek (brachy: short; dactylos: digit). It indicates shortening of digits due to abnormal development of phalanges, metacarpals, or both. Brachydactyly is one of the various described categories of hand malformations. Although it means "short finger", it has a clinical spectrum ranging from minor digital hypoplasia to complete aplasia ${ }^{2}$.

The isolated brachydactyly can be associated with subtle other malformations. It is often associated with hyponychia ${ }^{3}$. Brachydactyly may also be accompanied by other hand malformations, such as syndactyly, polydactyly, reduction defects, or symphalangism. In isolated cases of brachydactyly, are mostly inherited as autosomal dominant with variable expressivity and penetrtance ${ }^{2}$.

\section{Brachydactyly type A2 (BDA2)}

[Online Mendelian Inheritance in Man (OMIM): 112600] Synonym: MOHR-WRIEDT TYPE
BRACHYDACTYLY) BDA2 is characterized by hypoplasia/aplasia of the $2^{\text {nd }}$ middle phalanx of the index finger and sometimes little finger. It was first described by Mohr and Wriedt ${ }^{5}$. It is characterized by a triangularshaped middle phalanx in the index fingers and second toes. With more severe deformity, the index finger is curved radially. Deformity of the $2^{\text {nd }}$ toe is a more consistent finding than deformity of the index finger. The big toes show malformation of the proximal phalanx resulting in fibular deviation of the distal phalanx, while all other toes have rudimentary middle phalanges causing tibial deflection of their distal phalanges. Temtamy and McKusick ${ }^{1}$ reported a family, the fourth in the literature, with 16 affected members in four generations.

The family described here is one of the extremely rare families with brachydactyly type A2. Curiously they all had (at least the two examined) had only index fingers involved which is not the more consistent deformity.

It is a very rare digital malformation. There is no epidemiological study found in the literature. Clinical and radiological evaluation of the hands and curved index finger, together with the second toe should be done for diagnosis. The characteristic feature is seen as triangular shaped middle phalanx of the index fingers and second toes. Studied families demonstrate autosomal dominant inheritance.

Type A2 brachydactyly can be caused by mutation in the human bone morphogenetic protein receptor $1 \mathrm{~B}$ gene (BMPR1B) on chromosome 4q, that affect cartilage formation in a dominant-negative manner ${ }^{6}$. Kjaer et ${ }^{7} l^{7}$ found that sparing of the $4^{\text {th }}$ finger distinguishes the MohrWriedt type BDA2 from BDA2 caused by mutations in BMPR1B.

There is no specific management or treatment that is applicable to all forms of brachydactyly. Plastic surgical correction is only indicated in patients where hand function is affected or for cosmetic reasons, but is not needed for most of the cases. Sometimes physical therapy and ergotherapy may be required for improving hand function. Prognosis depends on the nature and severity of the abnormalities associated with various syndromes.

The hand phenotype in isolated forms of brachydactyly allows identification of 11 types, with minimal degrees of phenotypic overlap ${ }^{2}$. Normally, the inheritance is of autosomal dominant pattern with variable expression and penetrance. There are extensive numbers of syndromic forms. All the cases of brachydactyly should have thorough clinical evaluation 
of both hands and feet including radiological evaluation, clinical evaluation of the whole body of the patient, family history (taking non-penetrance into account). Ideally at least all the first degree relatives should have clinical evaluation. Analysis of the available photographs of the dead members of the family should be done. Specific investigations should evaluate symptoms from other systems. For research purpose and patient counseling molecular analysis is justified.

\section{References}

1. Superti-Furga A, Unger S. Nosology and classification of genetic skeletal disorders: 2006 revision. Am J of Med Genetics Part A. 2007,143A(1),1-18.

2. Temtamy SA, Aglan MS. Brachydactyly. Orphanet J Rare Dis. 2008;3:15.
3 Seitz CS, Hamm H. Congenital brachydactyly and nail hypoplasia: clue to bonedependent nail formation. British Journal of Dermatology.2005;152(6):1339-42

4. Mohr OL, Wriedt C. A New Type of Hereditary Brachyphalangy in Man. Washington: Carnegie Inst; 1919. pp. 5-64.

5. Jones GB.Delta phalanx. J Bone Joint Surg.1964, 45A:1704.

6. Lehmann K, Seemann P, Stickler S, et al. Mutations in bone morphogenetic protein receptor 1B cause brachydactyly type A2. Proc Natl Acad Sci.USA. 2003;100:12277-82.

7. Kjaer $\mathrm{KW}$, Eiberg $\mathrm{H}$, Hansen $\mathrm{L}$ et al. A mutation in the receptor binding site of GDF5 causes MohrWriedt brachydactyly type A2. J Med Genet. 2006;43:225-31.

\section{How to cite this article?}

Haldar SK, Khan I, Paira SK, Mukherjee R. Familial Brachydactyly in an Indian Family; A case report. J Nepal Paediatr Soc 2011;31(3):241-2243. 